\title{
MENYOAL TEKS NORMATIF SEPUTAR KUBUR (KAJIAN SANAD DAN MATAN HADIS TENTANG ZIARAH KUBUR)
}

\author{
Abusiri \\ Sekolah Tinggi Agama Islam ALHIKMAH Jakarta \\ Abusiri2014@gmail.com
}

\section{Abstract}

Until recently, the hadith related to the pilgrimage of the grave is not seldom questioned, both regarding the status of the isnad, quality as well as understanding the contextualism meaning of matan. Because of this, so great that can set about understanding the hadith this grave pilgrimage proportionately, namely when the hadith is understood by textual, contextual, universal, temporal, and local.

To find out a comprehensive understanding of the hadith about this grave pilgrimage, it must be known in advance the meaning behind the text or the intent behind the prohibition on grave pilgrimage for women, making it a place of worship, and giving it lights or lighting. This can be done by connecting with other similar verses history or see asbāb al-wurüd of al-hadith is first done after the criticism of matan and isnad.

From the study in this article, it appears that at first the grave pilgrimage for women, made the grave a place of worship, and gave it lighting (lights) are indeed prohibited with the intention of keeping the aqidah or monotheism of Allah, preventing dependency to people who have died, and avoid shirk by extolling the grave, and avoid many lamented over their fate and a lack of patience for a woman. But after missing it concerns-severely screwing things, 
everything should be with the intention of adding to the faith. So, the existence of the ban because of maslahah and it's possible too because of maslahah.

Keywords: Isnad, Matan, Hadith, Grave 


\section{Abstrak}

Sampai saat ini, hadis yang berkaitan dengan ziarah kubur tidak jarang dipersoalkan, baik mengenai status sanad, kualitas matan maupun pemahaman makna kontekstualnya. Karena itu, begitu besar urgensinya bisa mendudukkan pemahaman hadis tentang ziarah kubur ini secara proporsional, yakni kapan hadis tersebut dipahami secara tekstual, kontekstual, universal, temporal, maupun lokal.

Untuk mengetahui pemahaman secara komprehensif tentang hadis ziarah kubur ini, harus diketahui terlebih dahulu makna dibalik teks atau maksud dibalik larangan ziarah kubur bagi wanita, menjadikannya sebagai tempat ibadah, dan memberinya penerangan. Hal ini bisa dilakukan dengan cara menghubungkan dengan riwayat lain yang semakna atau melihat asbab al-wurud dari hadis tersebut setelah terlebih dahulu dilakukan kritik sanad dan matannya.

Dari kajian dalam artikel ini tampak bawa ziarah kubur bagi wanita, menjadikan kubur sebagai tempat ibadah, dan memberinya penerangan (lampu) pada awalnya memang dilarang dengan maksud memelihara aqidah atau ketauhidan Allah SWT, mencegah ketergantungan kepada orang yang telah meninggal, dan menghindarikesyirikan dengan mengagung-agungkan kubur, dan menghindari banyak keluh kesah dan kurangnya kesabaran bagi wanita. Namun setelah kehawatiran-kekhawatiran itu hilang, semuanya menjadi boleh dengan maksud menambah keimanan. Jadi, adanya larangan karena adanya maslahah dan diperbolehkannyapun karena maslahah.

Kata Kunci: Sanad, Matan, Hadis, Kubur 


\section{A. PENDAHULUAN}

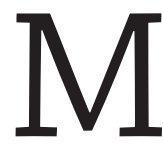

elihat kubur yang sunyi -dimana setiap pelita kehidupan semua orang, baik kaya maupun miskin, kuat maupun lemah akan padam dengan tiga lembar kain kafan di bawah tanah- akan menggerakan hati dan jiwa seseorang, serta mengurangi ketamakannya. Bila seseorang melihatnya dengan kacamata Hikmah, ia akan dapat mengambil pelajaran dari peristiwa ini. Ia akan berpikir dan berkata pada diri sendiri: "kehidupan dunia adalah sementara, enam puluh atau tujuh puluh tahun, dan akan berakhir dengah kemusnahan. Sungguh tidak sebanding dengan usaha manusia dalam mencari harta dan kedudukan, sehingga tak jarang menganiaya diri sendiri dan orang lain.

Namun demikian, teks normatif (hadis) yang berkaitan dengan hal tersebut tidak jarang dipersoalkan, baik mengenai status sanad, kualitas matan maupun pemahaman makna kontekstualnya. Karena itu, begitu besar urgensinya bisa mendudukkan pemahaman hadis tentang ziarah kubur ini secara proporsional, yakni kapan hadis tersebut dipahami secara tekstual, kontekstual, universal, temporal, situasional maupun lokal. Sebab, pemahaman yang kaku, radikal dan statis sama artinya menutup keberadaan Islam yang moderat dan selalu sesuai dengan segala situasi konsisi (şāliḥ li kulli zamān wa makān). Jadi, hadis harus dipahami sesuai situasinya dan diadaptasikan ke dalam konteks kekinian. ${ }^{1}$ Untuk itulah artikel ini dihadirkan, yakni, guna menentukan status sanad, kualitas matan, dan kandungan maknanya serta kontekstualisasi pemahaman terkait hadis tentang ziarah kubur bagi wanita dan memberinya penerangan.

\section{B. PENYAJIAN HADIS}

Penyajian hadīs tentang ziarah kubur ini diawali dengan melakukan takhrỉjal-hadīs. Adapun kitab hadīs yang menjadi sumber utama adalah kitab hadīs yang Sembilan atau kutub al-tis'ah, yaitu Sahīh al-Bukharī, Sahīh Muslim, Sunan Abī Daūd, Sunan al- Tirmizi,

1 Suryadi, Metode Kontemporer Memahami Hadis Nabi (Perspektif Muhammad al- ghazali dan Yusuf Qardhawi), (Yogyakarta: TERAS, 2008), h. 4. 
sunan al-Nasa'ì, Sunan Ibn Mājah, Sunan al-Dārimī, Muwattha' Mālik, dan Musnad Imam Ahmad bin Hanbal. Hadīs yang dibahas dalam penelitian ini adalah hadīs al-Jannatu tahta aqdām al-ummahāt. selain itu, digunakan juga penelusuran lewat mausu'ah hadis online. Untuk melacaknya, digunakan kitab Mu'jam al-Mufahras li Alfäzīl Hadīs al-Nabawi, dan Miftāh kunūz al-Sunnah, karya A.J. Winsink dan ditahkik oleh Muhammad Fuad al-Baki. ${ }^{2}$ Dari penelusuran tersebut ditemukan 26 sumber yang mencantumkan hadis tersebut dengan redaksi yang sama atau mirip dan semuanya bersumber dari sahabat Abdullah ibn Abbas. Berikut di sajikan contoh redaksi hadis lengkap dengan silsilah sanadnya:

Hadis riwayat Ahmad ibn Hanbal. ${ }^{3}$

$$
\begin{aligned}
& \text { حدثنا عبد الله حدثنى أبى ثنا محمد بن جعفر ثنا شعبة ثنا محمد بن جحادة عن } \\
& \text { ابى صالح عن ابن عباس قال: لعن رسول الله صلى الله عليه وسلم زائرات القبور } \\
& \text { والمتخذين عليها المساجد والسرج. }
\end{aligned}
$$

"Diriwayatkan dari Abdullah, dari Bapak saya (Ahmad ibn Hanbal) dari Muhammad bin Ja'far dari Syu'bah dari Muhammad bin Juhadah dari Abi Salih dari ibn Abbas berkata: "Rasulullah SAW melaknat/ mengutuk wanita berziarah kubur dan kaum laki-laki yang menjadikan kuburan sebagai tempat ibadah (masjid) dan memberinya lampu".

\section{SKEMA SANAD}

Adapun skema sanad dari jalur sanad hadis yang ditakhrij dalam artikel ini adalah sebagai berikut:

2 A.J. Winsink, Al-Mu'jam al-Mufahras li al-Faz al-Had'îs al-Nabaw'ì, (Leaden: Breil, 1936).

3 Sebagai sampel dalam melakukan takhrij ini haya mencantumka satu hadis dari riwayat Ahmad ibn Hanbal. Untuk lengkapnya lihat Ahmad bin Hanbal, musnad (Beirut: Dar al-Fikr, tt), hlm. 229, 324, 356; Abu Daud Sulaiman bin Asy'as, al-Jami' as-Sahih, (t.p: Dar al-Fikr, tt.) III, hlm. 172; Jalaluddin al-Suyuti, Syarh Sunan an-Nasa'i (Beirut: Dar al-Fikr, tt.), IV, hlm. 400; Abu Isa at-Turmuzi, al-Jami' as-Sahih (Makkah: al-Maktabah at-Tujjariyah Mustaf Ahmad al-Baz, tt.), II, hlm. 136; Ibn Majah, Sunan Ibn Majah (tp: Dar al-Fikr, tt.) I, hlm. 487. Untuk masing-masing bunyi teks hadisnya bisa dilihat di bagian lampiran. 


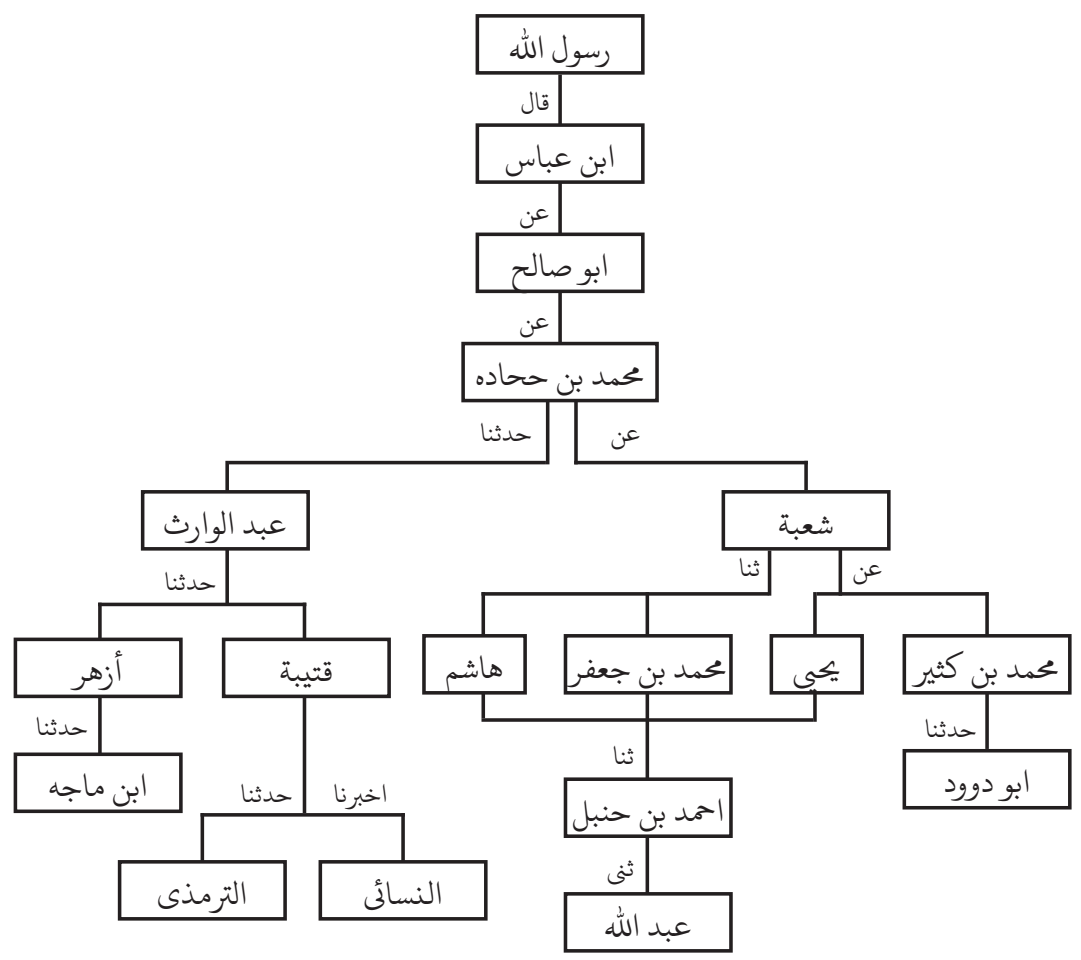

\section{KAJIAN SANAD DAN MATAN HADIS}

Dalam studi hadis, kajian sanad dan matan dikenal dengan istilah kritik hadis atau naqd al-hadìs. Ini merupakan upaya menyeleksi hadīs agar dapat diketahui mana hadīs yang Shahīh dan mana hadīs yang tidak şaḥih . Hadīs terdiri dari sanad dan matan, oleh karena itu obyek kajian hadīs mencakup pada kajian sanad atau naqd al-sanad seringkali diistilahkan dengan naqd al-kharij atau kritik ekstern dan kajian matan atau naqd al-matan atau naqd al-dakhīl atau kritik inter. ${ }^{4}$

Kajian atau kritik sanad merupakan bahagian dari penelitian hadīs, oleh karena itu pembahasan tentang sanad merupakan hal yang urgen untuk dibahas. Sanad itu sendiri secara bahasa adalah

4 Suryadi, Metode Kontemporer Memahami Hadis Nabi (Perspektif Muhammad al- ghazali dan Yusuf Qardhawi), Yogyakarta: TERAS, 2008), h. 14-15 
sandaran atau sesuatu yang dijadikan sandaran, dikarenakan setiap hadīs selalu bersandar kepadanya. ${ }^{5}$ Sedangkan menurutistilah sanad adalah rangkaian para periwayat yang menyampaikan kita kepada matan hadīs, yang meliputu dua unsur penting yaitu nama-nama periwayat yang ada dalam rangkaian hadīs tersebut dan lambang periwayatan yang digunakan dalam periwayatan hadīs tersebut oleh periwayatnya masing-masing. ${ }^{6}$ Dari pengertian di atas, dapat dipahami bahwa penelitian sanad adalah upaya pengecekan dan analisa rangkaian periwayatan hadīs yang menyampaikan kepada matan hadīs.

Kajian (kritik sanad) dilakukan dengan menelusuri kapasitas intelektual dan kredibilitas para periwayat yang ada dalam hadīs yang diteliti, serta lambang-lambang tahammmul wa ada yang digunakan. Secara umum ada lima kreteria yang harus dipenuhi oleh sanad hadīs sebagaimana dikemukakan oleh ibn Shalah, agar sebuah sanad hadīs tersebut dapat diterima atau dikatakan şahịh, yaitu sanad hadis harus bersambung, periwayat yang ada dalam hadīs tersebut harus orang yang adil dan dhabit, ${ }^{33}$ Sanad tersebut haruslah terhindar dari illat dan syadz. ${ }^{7}$

Matan hadis dalam pengertian istilah sebagai kalimat yang ada setelah berakhirnya sanad, atau ada yang mendefinisikan dengan beberapa lafal hadīs yang membentuk beberapa makna. ${ }^{8}$ Dengan demikian matan adalah bahagian yang tidak dapat dipisahkan dari sanad, oleh karena itu suatu penelitian atau krtik sanad haruslah diiringi dengan penelitian matan, mengingat suatu hadīs yang Shahīh sanad-nya, tidak secara otomatis matan hadīsnya berkualitas Shahīh juga. Ada dua kreteria sebuah matan dapat dinyatakan şaḥịh,

5 Ali al-Qari, Syarh Nukhbah al-Fìkr, (Beirut: Dar al-Kutb al-Ilmiah, 1978M), h. 194; Syuhudi ismail, Metodologi Penelitian hadīs Nabi, (Jakarta: Bulan Bintang, 2007), h. 21

6 Lambang periwayatan yang dimaksud seperti, sami'tu, haddatsana, akhbarona, 'an, anna. Syuhudi ismail, Metode Kontemporer, h. 12; M.M. a'zimi, Dirasat al-Had'îs al-Nabaw'ì, (t.tp: Jamiah al-Riyard, 1396 H), h. 391, Muhammad Ajjaj al-Khatib, Ushūl al-Had'ìs"Ulumuhu wa musthalahuhu, (Beirut: Dar al-ma'rifah, 1963M), 32-33

7 Abd al-Rahman ibn Shalah sebagaimana dalam Nur al-Itr, 'Ulūm al-Had'īs, (Al- Madinah alMunawwarah: al-Maktabah al-'ilmiyyah, 1927), h.10. Suryadi, Metode kontemporer, h. 14

8 Abdul Majid Khon, Ulumul Hadis, (Jakarta: Amzah, 2008), h. 103 
yaitu matan tersebut terhindar dari illat ${ }^{9}$ dan syadz. ${ }^{10}$

Muhammad Thahir al-Jawabi mengemukakan kritik matan hadīs mencakup, pertama: kritik dalam upaya menentukan benar tidaknya matan hadīs tersebut, kedua: kritik matan dalam rangka mendapatkan pemahaman yang benar mengenai kandungan yang terdapat dalam matan hadīs. ${ }^{38}$ Kedua cakupan di atas memang tidak dapat terpisahkan, karena penelitian matan hadīs harus mengungkap kandungan matan hadīs agar diketahui keotentikan matan hadīs tersebut dan sebaliknya.

Penentuan tolak ukur ke-şahìh-an matan hadīs yang dikemukakan oleh para ulama' sangat beragam. Penggunaan tolak ukur tersebut disesuaikan dengan masalah yang bersangkutan, AlKhatib al-Baghdadi misalnya, mengemukakan syarat-syarat matan hadīs yang maqbul adalah:

1. Tidak bertentangan dengan akal yang sehat

2. Tidak bertentangan dengan hukum al-Qur'an yang muhkam

3. Tidak bertentangan dengan hadīs yang mutawatir

4. Tidak bertentangan dengan amalan ulama salaf

5. Tidak bertentangan dengan dalil yang telah pasti

6. Tidak bertentangan dengan hadīs ahad yang kualitasnya lebih tinggi. ${ }^{11}$

Jumhur ulama' menyatakan bahwa ciri-ciri matan hadīs yang palsu itu adalah:

1. Sususnan bahasanya rancu

2. Kandungan matannnya sangat bertentangan dengan akal sehat, sangat sulit diinterpretasikan secara rasional

3. Kandungan matan bertentangan dengan hokum alam (sunnnah Allah), fakta sejarah, petunjuk al-qur'an, hadīs yang mutawatir

9 Illat dalam matan hadis adalah sebab yang tersembunyi yang merusak kualitas hadīs, keberadaannya menyebabkan hadīs yang pada lahirnya tampak berkualitas Shahīh menjadi tidak Shahīh.Ibnu Shalah, 'Ulūm al-Had'ìs, (Al-Madinah al-Munawwarah: al-Maktabah al- Ilmiyah, 1972M), h. 81. Syhudi Ismail, Kaedah, Op. cit., h. 130

10 Syadz dalam matan hadiss yaitu secara bahasa adalah ganjil, terasing atau menyalahi aturan, yakni periwayatan orang tsiqoh bertentangan dengan periwayatan orang yang lebih tsiqoh. Lihat Shalah al-Din ibn Ahmad Al-Idlibi, Manhaj Naqd al-Matn, (Beirut: Dar al-Afaq al- Jadidah, 1983M/1403H), h. 192; Abdul Madjid Khon, 'Ulūm al-Had'ìs, h. 152-153

11 Abu bakar bin Ali tsabit al-Khatib al-Baghdahdi, Kitab al-Kifäyah Fì Ilm al-Riwāyah, (Mesir: Matba'ah al-Sa'adah, 1972), h. 206-207 
yang telah mengandung petunjuk secara pasti

4. Kandungan matannnya di luar kewajaran diukur dari petunjuk umum ajaran Islam. ${ }^{12}$

Dari kreteria kritik matan yang telah dikemukakan di atas dapat dipahami bahwa kreteria penelitian atau kritik matan hadīs secara umum adalah pengujian dengan al-Qur'an, hadīs yang lebih kuat atau şahịh, rasionalitas suatu matan hadīs, logika, ilmu pengetahuan atau penemuan ilmiah, fakta atau historis. Apabila matan suatu hadīs bertentangan dengan empat kreteria kritis matan di atas, maka suatu matan hadīs tidak dapat dikatakan şahịh

Langkah awal dalam kajian hadis ini adalah melakukan takhrij al-hadiś. Takhrij hadis ini dilakukan untuk menemukan hadis-hadis yang setema dan mengetahui silsilah rawinya (rangkaian sanadnya) serta kwalitas matannya. ${ }^{13}$ Dalam melakukan takhrij hadis ziarah kubur ini, penulis menggunakan Mausu'ah Kutub at-Tis'ah dan aplikasi Mausu'ah Hadis online pada laman www.islamweb.net. Laman mausu'ah hadis online ini tidak hanya memuat kutub at-tis'ah namun juga kitab-kitab hadis lainnya, seperti Usd al-Gabah karya Ali ibn Al-Asir (w. 630 H), ma'rifah as-sahabah karya Abu Nu'aim al-Asbihani dan sebagainya.

Apabila kita melakukan penelusuran hadis tentang ziarah kubur di atas dengan kata kuci (الَْسَاجِحَ وَالشُرُجْجَ) melalui Mausu'ah Hadis online, maka kita akan menemukannya hadis tersebut bersumber dari sahabat Abdullah ibn Abbas. Dalam penelusuran

12 Mustafa al-Shiba'i, al-Sunnah wa Makānatuhā Fì al-Tasyrī’ al-Islām, (Beirut: Dar alQaumiyyah, 1966, h. 96-100, Muhammad Sabbagh, al_hadīs al-Nabaw'ì, (T.tp: al- Maktabah alIslāmi, 1997M/1392H), h.132-134, Subhi al-shaleh, "Ulum al-Had'ìs wa Musthālahuhū, (Beirut: Dār al-Ilm Li al-Malayi, 1977), h.264-266

13 Kajian sanad (kritik sanad) dilakukan dengan menelusuri kapasitas intelektual dan kredibilitas para periwayat yang ada dalam hadis yang diteliti, serta lambang-lambang tahammmul wa ada yang digunakan. Secara umum ada lima kreteria yang harus dipenuhi oleh sanad hadīs sebagaimana dikemukakan oleh ibn Shalah, agar sebuah sanad hadis tersebut dapat diterima atau dikatakan şahịh, yaitu sanad hadīs harus bersambung, periwayat yang ada dalam hadīs tersebut harus orang yang adil dan dhabit, Sanad tersebut haruslah terhindar dari illat dan syadz. Lihat, Abd alRahman ibn Shalah sebagaimana dalam Nur al-Itr, 'Ulūm al-Had'ìs, (Al-Madinah al-Munawwarah: al-Maktabah al-'ilmiyyah, 1927), h.10; Suryadi, Metode kontemporer h. 14; Syuhudi Ismail, Metodologi Penelitian Hadis, (Jakarta: Bulan Bintang, 1999), h. 44. Syuhudi menyebutkan bahwa Takhrijul Hadis dilakukan untuk 1) mengetahui asal-usul riwayat hadis yang akan diteliti. 2) mengetetahui seluruh riwayat bagi hadis yang diteliti. 3) mengetahui ada atau tidaknya syahid dan muttabi' sanad yang diteliti. 
lewat mausu'ah hadis online ditemukan informasi sebagai berikut: ${ }^{14}$

\begin{tabular}{|c|c|c|c|c|c|c|c|}
\hline 5 & طرف الحديث & الصحابي & اسم الكتاب & أفق & العزو & المصنف & سنة الوفاة \\
\hline 1 & لعن رالمتخذين عليها المساجد الله والسرج & عباس الله بن & الترمذي & एव & re. & 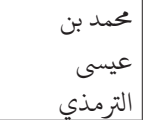 & 107 \\
\hline s & لمن رسول الله زائرات القبور & عبد الله بن & سنن أبي داود & SAC) & רזיז & أبو داود & svo \\
\hline$r$ & لمتن رسول الله زائرات القبور & عبد الله بن & سن الصغرى النسئى & r. & r.थr & النسائي & $r \cdot r$ \\
\hline$\varepsilon$ & زائرات القبور المتخذين عليها & عبد الله بن & مسند أحمد & $190 \varepsilon$ & וT.r & أحمد بن حنبل & (q) \\
\hline 。 & لمتن رسول الله زائرات القبور & عبد الله بن & مسند أحمد & ८१९६ & $\mu \cdot \Lambda$ & أحمد بن حنبل & (q) \\
\hline 1 & لعن رسول الله زائرات القبور & عبد الله بن & & 5170 & sqvV & أحمد بن حنبل & (q) \\
\hline $\mathrm{v}$ & لمتن رسول الله زائرات القبور & عبد الله بن & مسند أحمد & $10 . \varepsilon$ & 1091 & أحمد بن حنبل & (थ) \\
\hline$\wedge$ & لمن رسول الله زائرات القبور & عبد الله بن & حبان & reoq & ma. & أبو حاتم بن & ros \\
\hline 9 & لعن المتخذات عليها المساجد والئرات القبور & عبد الله بن & حبان & reOA & riva & أبو حاتم بن & ros \\
\hline 1. & لمتن رسول الله زائرات القبور & عبد الله بن & الصحيحين & דואו & $\begin{array}{l}: 1 \\
r V \varepsilon\end{array}$ & | الناكم & $\varepsilon .0$ \\
\hline 11 & المتخذين عليها المساجد والسرب اللهرات القبور & عبد الله بن & المبرى & rlov & [INI & النسائي & $\mu$ \\
\hline is & المتخذات عليها المساجد واللهرات القبور & عبد الله بن & المبرى & I777 & VA: $\varepsilon$ & البيهتي & EON \\
\hline זו & المتخذات عليها المساجد والسرج الله زوارج & عبد الله بن & 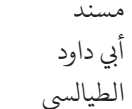 & SAEV & {$[107$} & |أبو داود & $r \cdot \varepsilon$ \\
\hline $1 \varepsilon$ & زائرات القبور المتخذات عليها & عبد الله بن & المعد ابن & 1591 & $10 .$. & الجوهري الجعد & זr. \\
\hline
\end{tabular}

14 http://library.islamweb.net/hadith/index.php; http://library. islamweb.net/hadith/ hadithsearch.php. diakses 9 Juli 2017. 


\begin{tabular}{|c|c|c|c|c|c|c|c|}
\hline r & طرف الحديث & الصحابي & اسم الكتاب & أفق & العزو & المصنف & سنة الوفاة \\
\hline 10 & لمتخذات عليها المساجد الله والسرات القبور & عبد الله بن & أبي شيبة ابن & $110 \mathrm{vo}$ & $1195 \varepsilon$ & ابن ابي شيبة & sto \\
\hline 17 & لمتخذات عليها المساجد والماترات القبور & عبد الله بن & مصنف أبي شيبة & VTVq & VIST & ابن ابي شيبة & sto \\
\hline iv & 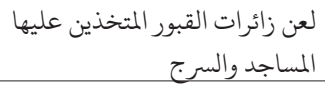 & عبد الله بن & للمبرانم الكبير & $1007 \mathrm{~V}$ & irveo & سليمان بن الطبراني & rq. \\
\hline 11 & 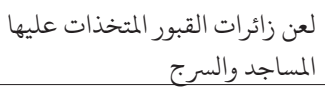 & عبد الله بن & الأعرابم ابن & אזר & איד & ابن الأعرابي & $r \varepsilon$. \\
\hline 19 & لمتن رسول الله زائرات القبور & عبد الله بن & اللمنتقاة عن الفئد & of & or & الحَّي بن عمر & r 17 \\
\hline r. & زالمساجد والسرج القبور المتخذين عليها & عبد الله بن & لاسن ومنسوخه الحديث & $r \cdot \Lambda$ & r.o & ابن شاهين & r 10 \\
\hline (I) & والمتخذين عليها المساجد والمبر المبرج & عبد الله بن & شرح السنة & 0.1 & 01. & الحسين بن البغود & 017 \\
\hline rs & زائرات القبور المتخذين عليها & عبد الله بن & لمشكل الآثار & \&10 & EVES & الطحاوي & rel \\
\hline r & زائرات القبور المتخذين عليها & عبد الله بن & لمشكل الآثار & Elor & $\varepsilon V \varepsilon 1$ & الطحاوي & rel \\
\hline$\tau \varepsilon$ & لمتخذين عليها المساجد والسرارات القبور & عبد الله بن & عبد البرهيد لابن & 00 . & 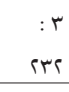 & 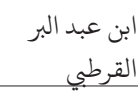 & \& \\
\hline 10 & لمنتخذين عليها المساجد والسر المئرات للقبور & عبد الله بن & التمهيد لابن & $0 \leqslant 9$ & 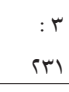 & القرطبي البر البر & 纟ाT \\
\hline 57 & المتخذين عليها المساجد والسرب اللهرات القبور & عبد الله بن & البخيخ بغداد & 5719 & $\begin{array}{l}: 1 \\
751\end{array}$ & 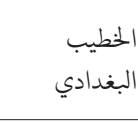 & $\varepsilon 7 r$ \\
\hline
\end{tabular}

\section{E. BIOGRAFI RAWI}

\section{Jalur Ahmad bin Hanbal}

\section{a. Abdullah}

Nama lengkapnya adalah Abdullah bin Ahmad bin Muhammad bin Hanbal bin Hilal bin Asad asy-Syaibani, 
al-Bagdadi, al-Zuhli dengan kunyah Abu Abdillah dan Abdurrahman, beliau dilahirkan pada tahun $213 \mathrm{H}$ dan wafat pada tahun $290 \mathrm{H}$.

1) Guru-gurunya dalam meriwayatkan hadis: Ayahnya sendiri (Ahmad bin Muhammad bin Hanbal, Ibrahim alHajjaj, Ahmad bin Sami' al-Bagawi, Abdullah bin Mu'adz dan sebagainya.

2) Murid-muridnya: an-Nasa'i, Abu Bakar bin Zaid, Ahmad bin Kamil dan lain sebagainya.

3) Pernyataan para ulama kritikus (hadis) tentang dirinya:

- Abu Ali as-Sufi berkata: "Abdullah bin Ahmad bin Hanbal sendiri pernah menyatakan bahwa mayoritas hadis yang ia riwayatkan adalah yang pernah ia dengar dari ayahnya minimal dua atau tiga kali."

- Al-Kuttab: Abdullah adalah śiqah

- An-Nasa'i: "śiqah".

- Abu al-Khalal: "Abdullah adalah seorang yang salih, punya gaya bahasa yang baik, serta pemalu. ${ }^{15}$

\section{b. Ahmad bin Hanbal}

Nama lengkapnya adalah Ahmad bin Muhammad bin Hanbal bin Hilal bin Asad asy-Syaibani, Abu Abdullah alMawardi, az-Zuhli, al-Bagdadi. Beliau wafat pada hari Jum'at tanggal 12 Rabi'ul Awal tahun $241 \mathrm{H}$.

1) Guru-gurunya dalam periwayatan hadis: Basyir bin Mufaddal, Jarir bin Abdil Hamid, Muhammad bin Ja'far, Abdullah bin Namr, Hasyim bin al-Qasim, Yahya bin Sa'id dan lain sebagainya.

2) Murid-muridnya: al-Bukhari Muslim, Abu Daud, Ibn Mahdi, asy-Syafi'i, Abu al-Walid, Husein bin Mansur, 
dan anaknya sendiri yakni Abdullah.

3) Pernyataan para ulama kritikus tentang dirinya:

- Abdul Raziq: "Belum pernah melihat seorang pun dari para rawi yang lebih mendalam ilmunya serta lebih wara' daripada Ahmad bin Hanbal."

- Yahya bin Adam: "Ahmad bin Hanbal lebih unggul dari kami."

- Asy-Syafi'i,: “Tidak ada yang lebih zuhud, wara', dan tidak ada pula yang lebih tahu (dalam hal ilmu hadis) dibanding Ahmad bin Hanbal. ${ }^{16}$

\section{c. Muhammad bin Ja'far}

Nama lengkapnya adalah Muhammad bin Ja'far Abu Abdillah yang lebih dikenal dengan laqabnya yaitu Gundar. Beliau wafat di Basrah pada tahun $193 \mathrm{H}$.

1) Guru-gurunya dalam periwayatan hadis: Syu'bah bin Hujjaj, Abdurrahamn bin Abdillah, Abdullah bin Ja'far, Malik bin Anas, Hisam bin Hissan, dan lain sebagainya.

2) Murid-muridnya: Ahmad bin Muhammad bin Hanbal, Ishak bin Ibrahim, Hujjaj bin Yusuf, Kgalifah bin Khayyat dan sebagainya.

3) Pernyataan para ulama kritikus (hadis) tentang dirinya:

- Muhammad bin Sa'ad: "śiqah”.

- Abu Khatim al-Razi: "saduq, śiqah".

- Al-'Ajli: "śiqah": termasuk orang yang paling kokoh dalam hal hadis."

- Ibn Habban: "termasuk orang yang śiqah". ${ }^{17}$

\section{d. Syu'bah}

Nama lengkapnya adalah Syu'bah bin al-Hujjaj bin alWardi al-'Itki al-Azadi Abu Bastham al-Wasthi al-Basri. 
Menurut Ibn Sa'd beliau dilahrikan di Basrah pada tahun $83 \mathrm{H}$. dan wafat pada tempat yang sama tahun $160 \mathrm{H}$.

1) Guru-gurunya: Ibrahim bin 'Amr, Ibrahim bin Muslim, Isma'il bin Raja', Isma'il bin Abdurrahman, Muhammad bin Ishaq, Muhammad bin Juhadah, Muhammad bin Ziyad dan sebagainya.

2) Murid-muridnya: Hasan bin Salih, Abu Daud, Muhammad bin Ja'far, Muhammad bin Kasir, Hasyim bin Abdul Mulk, Hasyim bin Basyir, Yahya bin Ibad, Yahya bin Sa'id dan sebagainya.

3) Pernyataan para ulama kritikus mengenai dirinya:

- Sufyan al-Sauri: "Amirul mu'minin dalam hal hadis".

- Yahya bin Sa'id al-Qattan berkata: "Saya belum pernah melihat seirang pun yang lebih baik dari Syu'bah dalam hal hadis".

- Abu Daud as-Sajsatani: "Di dunia ini tidak ada yang lebih baik hadisnya dibanding Syu'bah."

- Abu Talib berkata dari Ahmad: "Jika tidak karena Syu'bah, maka hilanglah hadis-hadis tentang hukum."18

\section{e. Muhammad bin Juhadah}

Nama lengkapnya adalah Muhammad bin Juhadah alAudi al-Ayami al-Kufi. Beliau wafat pada tahun $131 \mathrm{H}$ di Kufah.

1) Guru-gurunya dalam periwayatan hadis: Anas, Ziyad bin Alaqah, Abi Hazm, Abul Jabbar bin Wa'il, Ismail bin Abi Kald, Bazam Abu Salih, Zakwan Abu Salih, Zaid bin al-Haris dan sebagainya.

2) Murid-muridnya: anaknya sendiri yakni Isma'il, Syu'bah bin al-Hujjaj, Isma'il bin Yunus, Abdul Waris bin Sa'id, Ziyad bin Abdillah dan sebagainya.

18 Ibn Hajar, Tahzib., Juz IV, hlm. 341. 
3) Pernyataan para kritikus mengenai dirinya:

- Ahmad bin Hanbal berkata: "Muhammad bin Juhadah termasuk śiqah."

- Usaman bin Abi Syaibah: “śiqah, la ba'sa bih.

- An-Nasa'i: "śiqah”.

- Al-'Ajli: śiqah. ${ }^{19}$

\section{f. Abu Shalih}

Nama lengkapnya adalah Bazam Abu Shalih Maula Ummu Hani' al-Hasyimi al-Kufi.

1) Guru-gurunya: Ali, Ibn Abbas, Abu Hurairah, Ummu Hani'.

2) Murid-muridnya: al-A'masy, Ismail bin Abi Khalid, Isma'il bin Abdurrahman, Muhammad bin Juhadah, Muhammad bin as-Sa'ib.

3) Penilaian para ulama mengenai dirinya:

- Yahyaa bin Ma'in: "la ba’sa bih."

- Al-'Ajli: "śiqah".

- Ibn Syahin men-śiqahkannya.

- Abu Hatim al-Razi: "hadisnya tertulis (yuktab hadīśuhu), tapi tidak bisa dijadikan hujjah. ${ }^{20}$

\section{g. Ibn Abbas}

Nama lengkapnya adalah Abdullah bin Abbas bin Abdul Muthalib al-Hasyimi, putra paman Rasulullah SAW yang mendapat julukan al-Khibr karena banyaknya ilmu yang beliau kuasai. Ibn Abbas wafat pada tahun $69 \mathrm{H}$. ada juga yang mengatakan tahun $68 \mathrm{H}$. di Tha'if.

1) Guru-gurunya dalam periwayatan hadis: Rasulullah SAW. Ayahnya, Ibunya (Umm al-Fadl), saudaranya (alFadl), bibinya (Maimunah), Abu Bakar, Umar, Usman,

19 Ibid., Juz IX, hlm. 92. Lihat juga Abu Khatim al-Razi, al-Jarh wa at-Ta'dil (Haidar al-Hindi: Majlis Da'irah al-Ma'arif, 1952), VII, hlm. 1227.

20 Ibn Hajar, Tahzib., Juz I, hlm. 416, Abu Khatim, al-Jarh., Juz II, hlm. 1738. 
Abdurrahman bin Auf, Mu'az bin Jabal, Abi Zar, Usamah bin Zaid, Khalid bin Walid, Aisyah dan sebagainya.

2) Murid-muridnya: Anaknya (Ali), Muhammad, cucunya (Muhammad bin Ali), Abdullah bin Ubaidillah, Abdullah bin Umar, Sa'labah bin al-Hakim, Abdurrahman bin 'Auf, Abu Shalih, Abdullah bin Ka'ab, dan sebagainya.

3) Penilaian para ulama mengenai dirinya:

- Abu Hurairah berkata: "ketika Zaid bin Sabit wafat telah tiada Hibru al-Ummah (tinta ummat) dan semoga Allah menjadikan Ibn Abbas sebagai gantinya."

- Ibn Abi al-Zinad dari Hisyam berkata: "saya belum pernah melihat seorang pun yang ilmunya seperti Ibn Abbas."

- Aisyah: "dia termasuk orang paling 'Alim dalam hal Hujjah.

- Diriwayatkan dari al-Zubair: "Rasulullah pernah

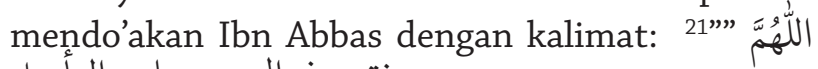
فقهه في الدين وعلمه التأويل

\section{Jalur Abu Daud ${ }^{22}$}

\section{a. Abu Daud}

Nama lengkapnya adalah Sulaiman bin Asy'as bin Syidad bin Amr bin Amir Abu Daud al-Sajsatani al-Hafiz. Beliau dilahirkan pada tahun $202 \mathrm{H}$. dan wafat pada tanggal 14 bulan Sawwal.

1) Guru-gurunya: Abu Salamah, Abu al-Walid, Muhammad bin Kasir al-Abdi, Muslim bin Ibrahim, Sulaiman bin Abdurrahman ad-Damisq dan lain sebagainya.

21 Ibn Hajar, Tahzib., Juz V, hlm. 276. Lihat juga CD hadis.

22 Karena nama-nama sanad setelah Muhammad bin Kasir sampai pada Ibn Abbas dalam jalur sanad Abu Daud ini sama dengan yang ada pada jalur sanad Ahmad bin Hanbal, maka disini penulis cukup menyebutkan Abu Daud dan Muhammad bin Kasir saja. 
2) Murid-muridnya: Abu Ali Muhammad bin Ahmad, Abu Isa, Abu Said, dan lain sebagainya.

3) Penilaian para ulama mengenai dirinya:

- Abu Bakar al-Khilal: "Abu Daud merupakabn imam ternama pada zamannya, dan termasuk orang yang wara'."

- Ahmad bin Muhammad bin Yasin: "Abu Daud merupakan pernhaal hadis, baik ilmunya maupun sanadnya serta memiliki derajad yang tinggi."

- Musa bin Harun: "Abu Daud di dunia diciptakan untuk hadis dan di akhirat untuk surga."23

\section{b. Muhammad bin Kasir}

Nama lengkapnya adalah Abu Abdillah Muhammad bin Kasir al-Basri. Beliau wafat pada tahun 223 H. di Basrah.

1) Guru-gurunya: "Sulaiman bin Mughirah, Syu'bah bin alHujjaj, Abdurrahman bin Amr dan sebagainya."

2) Murid-muridnya dalam berbagai literatur yang penulis jumpai tidak diosebutkan.

3) Penilaian para ulama mengenai dirinya:

- Ahmad bin Hanbal: "śiqah".

- Ibn Hibban: men-śiqahkan.

- Yahya bin Ma'in: tidak śiqah. ${ }^{24}$

\section{Jalur an-Nasa'i $\mathbf{i}^{25}$}

\section{a. An-Nasa'i}

Nama lengkapnya adalah Ahmad bin Sya'ib bin Ali bin Sinan bin Ba bin Dinar Abu Adirrahman an-Nasa'i al-Qadi al-Hafiz. Beliau dilahirkan pada tahun $215 \mathrm{H}$. dan wafat pada hari Senin tanggal 13 Safat tahun 303 H. di Palestina.

23 Ibn Hajar, Tahzib., Juz IV, hlm. 169-173.

24 Lihat CD hadis Kutub at-Tis'ah.

25 Untuk sanad Muhammad bin Juhadah, Abu Salih dan Ibn Abbas, lihat pada jalur sanad Ahmad bin Hanbal 
1) Guru-gurunya: Ahmad bin Nasr an-Naisaburi dan Abi Syuu'ib al-Susi.

2) Murid-muridnya: Abdul Karim (anaknya), Abu Bakar Ahmad bin Muhammad, Muhammad bin Mu'awiyah dan sebagainya.

3) Penilaian para ulama tentang dirinya:

- Abu Ali an-Naisaburi: “an-Nasa'i termasuk imam orang-orang Muslim dan imam dalam hadis tanpa ada yang menolaknya."

- Ibn Yunus: "Di samping sebagai imam hadis ia juga siqqah, subut dan hafiz."

- Abu al-Husein bin al-Mudzaffar: “an-Nasa'i termasuk orang yang rajin beribadah baik siang maupun malam, sungguh-sungguh dalam berjihad. ${ }^{26}$

\section{b. Qataibah}

Nama lengkapnya adalah Qataibah bin Sa'id bin Jamil bin Tarif bin Abdillah al-Saqafi Abu Raja' al-Bagillani. Beliau dilahirkan pada tahun $150 \mathrm{H}$. dan wafat pada bulan Sya'ban $240 \mathrm{H}$.

1) Guru-gurunya: Malik, Daud bin Abdirrahman, Abdul Waris bin Sa'id, Abdullah bin Yazid, Mu'awiyah bin Ammar dan sebagainya.

2) Murid-muridnya: at-Turmudzi, ibn Majah dengan perantara Ahmad bin Hanbal, Ahmad bin Sa'id adDarimi, an-Nasa'i, Abu Hatim, Ali al-Madini, Muhammad bin Abdillah dan lain sebagainya.

3) Penilaian para ulama mengenai dirinya:

- Yahya bin Ma'in dan Abu Hatim al-Razy: "śiqah".

- An-Nasa'i: "śiqah, saduq".

- Al-Hakim: "śiqah, ma’mun". 
- Ahmad bin Siyar: "subut"

- Ibn Hibban: "min al-mutqimin"27

\section{c. Abdul Waris}

Nama lengkapnya adalah Abdul Waris bin Sa'id bin Zakwan at-Tamimi al-Anbari Abu Ubaidah al-Basri. Wafat di Basrah pada tahun $180 \mathrm{H}$.

1) Guru-gurunya: Abdul Aziz bin Sahib, Yahya bin Ishak, Sulaiman at-Tamimi, Muhammad bin Ishak, Humaid bin Qais, Muhammad bin Juhadah, Muhammad bin Zubair dan sebagainya.

2) Murid-muridnya: Abdussamad (putranya), Affan bin Muslim, Ahmad bin Ubaidah, Abdullah bin Umar, Qataibah bin Sa'id, Muhammad bin Ziyad, dan lain sebagainya.

3) Penilaian para ulama mengenai dirinya:

- Abu Zar'ah al-Razi dan al-Ajli: "śiqah".

- Abu Hatim al-Razi: "śiqah, saduq".

- Muhammad bin Sa’ad: "śiqah, hujjah”.

- An-Nasa'i: "śiqah, subut". ${ }^{28}$

\section{Jalur at-Turmuzi ${ }^{29}$}

\section{At-Turmuzi}

Nama lengkapnya adalah Muhammad bin Isa bin Saurah bin Musa bin ad-Dahhaq Abu Isa at-Turmuzi. Wafat pada bulan Rajab tahun $279 \mathrm{H}$.

1) Guru-gurunya dalam literatur yang penulis temukan tidak diuraikan secara jelas, hanya saja disebutkan bahwa beliau mendengar hadis dari ulama Iraq dan Hijaz.

27 Ibid., Juz VIII, hlm. 358. Lihat juga CD hadis.

28 Ibn Hajar, Tahzib., Juz VI, hlm. 441. Abu Khatim al-Razi, al-Jarh., Juz. VI, hlm. 386. Lihat juga CD hadis Kutub at-Tis'ah.

29 Untuk rijal sanad mulai Qutaibah sampai Ibn Abbas, lihat pada jalur sanad Ahmad bin Hanbal. 
2) Murid-muridnya: Abu Hamid Ahmad bin Abdillah, Muhammad bin Mahbub, Mahmud bin Namir dan lain sebagainya.

3) Penilaian para ulama mengenai dirinya:

- Al-Khalili: "śiqah, muttafaq alaih".

- Al-Idrisi: "at-Turmuzi merupakan salah satu imama yang babnyak pengikutnya dalam ilmu hadis”.

- Al-Hakim Abu Ahmad: "tidak seorang pun yang menyamai Abu Isa dalam bidang ilmu dan wara.." ${ }^{30}$

\section{Jalur Ibn Majah ${ }^{31}$}

\section{a. Ibn Majah}

Nama lengkapnya adalah Muhammad bin Yazid arRub'i Abu Abdillah bin Majah al-Qazwaini al-Hafiz. Wafat pada tahun $273 \mathrm{H}$. ada pula yang menyatakan $275 \mathrm{H}$.

1) Guru-gurunya tidak disebutkan satu persatu hanya saja beliau pernah mendengar hadis dari ulama Khurasan, Iraq, Hijaz, Mesir, Syam dan sebagianya.

2) Murid-muridnya: Ali bin Abi Abdillah, Ibrahim bin Dinar, Ahmad bin Ibrahim, Husein bin Ali dan sebagainya.

3) Penilaian para ulama mengenai dirinya:

- Al-Khalili: "śiqah, muttafaq alaih, dapat dijadikan Hujjah dan pintar dalam hal hadis serta hafal dengannya.

- Ibn Tahir : "isi kitab "sunan" adalah cukup baik, tetapi di dalamnya juga terdapat hadis dha'if; setiap hadis yang diriwayatkan oleh Ibn Majah secara sendirian adalah dha'if. ${ }^{32}$

30 Ibn Hajar, Tahzib., Juz IX, hlm. 387.

31 Untuk rijal sanad mulai Abdul Waris sampai Ibn Abbas, lihat pada jalur sanad Ahmad bin Hanbal.

32 Ibid., hlm. 530-533. 


\section{b. Azhar}

Nama lengkapnya adalah Azhar bin Marwan ar-Raqasi an-Nawa'. Wafat pada tahun $243 \mathrm{H}$.

1) Guru-gurunya: Hammad bin Zaid, Abdul Waris bin Sa'id, Abdul A'la, al-haris bin Nubhan, dan sebagainya.

2) Murid-muridnya: at-Turmuzi, Ibn Majah, Musa bin Harun, dan sebagainya.

3) Penilaian para ulama mengenai dirinya:

- Abu Halim ibn Hibban: "mustaqim al-Hadis”.

- Musallamah al-Andalusi: "śiqah". ${ }^{33}$

\section{F. ANALISA KETERSAMBUNGAN SANAD}

Untuk mengetahui bersambung atau tidaknya masing-masing sanad, paling tidak, menurut penulis, ada tiga tolok ukur yang bisa dijadikan dasar penilain, yaitu: adat at-tahammul wa al-ada', penilaian para ulama (al-jarh wa al-ta'dil) dan adanya syahid dan mutabi'.

Pertama, dilihat dari segi lambang (periwayatan) yang digunakan, semua jalur sanad menggunakan tiga lambang yaitu haddasana, 'an dan qala. Kecuali an-Nasa'i ada tambahan lambang akhbarana.

Lambang atau simbol haddasana dan akhbarana merupakan adat tahammul dan ada' yang digunakan untuk menunjukkan bahwa sebuah hadis, dengan menggunakan simbol itu, diriwayatkan dengan metode as-sima', al-Qira'ah dan al-Ijazah. Lambang ini menunjukkan ke-muttaşil-an (ketersambungan) suatu sanad. Oleh karena itu, masing-masing sanad di atas, yang menggunakan simbol ini, bisa dipastikan atau kemungkinan besar antara guru dan muridnya pernah bertemu (لقاء) serta mendengar langsung hadis yang diriwayatkanya.

Adapun periwayatan dengan menggunakan lambang (عن)

33 Ibid., Juz I, hlm. 32. 
walaupun jarang dipakai oleh para ahli hadis untuk menunjukkan pada metode as-sima', namun bisa juga digunakan dan menunjuk riwayat bi as-sima' tersebut, dengan catatan apabila sebuah hadis yang memang diketahui bertemu dengan gurunya. Kaitannya dengan hal ini apakah Syu'bah, Muhammad bin Juhadah dan Abu Shalih yang menggunakan lambang tersebut dalam periwayatan di atas melakukan tadlīs atau tidak, akan dibahas pada kriteria kedua, yakni penilaian para ulama mengenai diri mereka.

Sedangkan lambang qala yang digunakan oleh Ibn Abbas dalam riwayat di atas menggambarkan bahwa Ibn Abbas menerima atau mendengar langsung hadis dari Rasulullah SAW. Hal ini sangat logis, karena Ibn Abbas adalah sahabat dan sekaligus keponakan beliau (putra Abdul Muttalib, paman Rasulullah SAW) yang pernah dido'akan: اللُّهَ فقهه في الدين وعلمه التأويل tentu saja pernah bertemu, menghadiri dan mendengar hadis yang disamapaikan Nabi SAW.

Kedua dari segi al-jarh wa at-Ta'dìl, mayoritas ulama kritikus hadis memberi penilaian positif (men-ta'dil) terhadap masingmasing rawi hadis di atas dengan kata-kata pujian seperti: la ba'sa bih, subut, saduq, wara', hafiz, zuhud, śiqah dan pujian-pujian lainnya. Hanya Ibn Tahir yang menilai bahwa seitap hadis yang diriwayatkan oleh Ibn Majah secara sendirian adalah da'if. Tetapi penilaian ini tidak berlaku untuk hadis di atas, karena hadis tersebut tidak hanya diriwayatkan oleh Ibn Majah. Di samping itu, dalam biografi masing-masing rawi di atas disebutkan antara guru dan muridnya atau salah satu di antara keduanya, hal ini mendukung ke-muttaşilan sebuah sanad.

Ketiga, dari segi adanya syahid dan muttabi'. Hadis yang sedang di-takhrij ini tidak memiliki syahid, karena hanya diriwayatkan oleh seorang sahabat, yakni Ibn Abbas. Sedangkan sanad yang memiliki muttabi' terlertak pada sanad-sanad ketiga dan keempat. Namun ketiadaan syahid dan ketiadaan mutabi' pada sanad pertama dan kedua serta mukharrij tidak mengurangi kekuatan para periwayat yang bersangkutan karena mereka adalah orang-orang yang śiqah, dan tidak ada seorang ulama pun yang mencelanya berkaitan dengan riwayat ini. Lagi pula ketiadaan syahid dan mutabi' terssebut 
bukan pada periwayat yang majhul dan mubham atau sanad yang terputus.

Dengan demikian berdasarkan ketiga kriteria di atas dapat dinyatakan bahwa semua sanad dari lima jalur sanad yang sedang di-takhrij adalah muttaşil (bersambung), dan status atau kualitas dari hadis tersebut adalah marfü" atau paling tidak menurut kriteria at-Turmuzi termasuk hadis Hasan Sahih.

\section{G. PEMAHAMAN MATAN HADIS}

Apabila diperhatikan bunyi teks hadis di atas, terlihat bahwa ada tiga pesan pokok yang ingin disampaikan. Pertama, larangan ziarah kubur bagi kaum wanita. Kedua, larangan menjadikan kuburan sebagai tempat ibadah, dan ketiga larangan memberi atau menyalakan lampu pada kuburan.

\section{Larangan ziarah kubur bagi kaum wanita}

Paraulama berselisih pendapat dalam menentukanlarangan yang terkandung dalam hadis tersebut. Apakah larangan itu berarti haram, makruh, atau bahkan menjadi boleh. Bagi yang mengartikannya sebagai "haram", mereka berdalil dengan pemahaman tekstual terhadap hadis di atas. Sedangkan yang mengartikan sebagai makruh mereka menghubungkannya dengan riwayat lain yang berbunyi "نهينا عن اتباع الجنائز ولم" يعزم علينا Sementara mereka yang membolehkan wanita melakukan ziarah kubur juga menghubungkan hadis itu

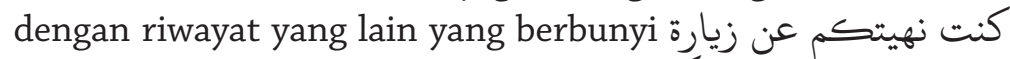
34. زوروا القبور فإنها تذكر للموت dan riwayat lain lagi القبور فزوروها

Pendapat yang disebut terakhir ini yang banyak diikuti oleh para ulama, karena khițāb dalam riwayat itu adalah umum, baik laki-laki maupun perempuan. Dengan demikian, menurut mereka (pengikut pendapat ketiga) larangan ziarah kubur bagi kaum wanita di-mansūkh dengan riwayat yang datang

34 Lihat Abu at-Tibb Muhammad Syamsul Haq, 'Aun al-Ma'bud Syarh Sunan Abu Daud (Madinah: Maktabah al-Salafiyah, 1979), II, hlm. 58. 
kemudian yang mengizinkannya. ${ }^{35}$

Dalam kitab Sunan at-Turmuzi juga disebutkan bahwa larangan ziarah kubur bagi wanita berlaku ketika belum ada izin (rukhsah) dari Nabi, namun setelah ada riwayat yang mengizinkannya, maka menjadi boleh. Demikian juga dikatan bahwa adanya larangan ini karena wanita banyak keluh kesah dan kurang kesabarannya ketika berkunjung kekuburan. ${ }^{36}$

Ada beberapa kriteria yang menyebabkan hukum ziarah "dianjurkan atau sunah" bagi perempuan menjadi makruh atau bahkan "haram" menurut pendapat sebagian ulama. Pertama, karena "jumlah atau mukthirāt." Hal ini sebagaimana disebut oleh Al-Qāḍi Muḥammad bin "Abdullāh Abū Bakr alIshbīlī al-Mālikī, dan al-Qurțubī sebagaimana disebut oleh Ibn Hajar al-'Asqalānī. ${ }^{37}$ Pengertian "jumlah/mukthirāt" ini dapat bermakna jumlah kunjungan ziarah maupun jumlah peziarah. Tujuan ziarah kubur ialah mengingat kematian sebagai sarana introspeksi diri dan mendoakan para ahli kubur. Kegiatan "ziarah" yang "terlalu sering" dan berlebihan dikhawatirkan akan melalaikan seseorang dari tujuan ziarah tersebut.

Kegiatan "ziarah" yang terlalu sering juga menjadi indikasi bahwa "peziarah" diduga masih "kehilangan" akan sosok orang yang sering diziarahi itu. Jika yang terakhir ini terjadi, maka peziarah boleh jadi mengabaikan pesan Nabi Saw untuk bersabar ketika terjadi "serangan pertama" yakni ketika musibah (kematian) terjadi dan membatasi kesedihan agar tidak berlarut-larut. Bagi seorang perempuan, sebagai istri atau orang tua dari anak-anak, kesedihan yang berlarutlarut dan kunjungan yang berlebihan ke pekuburan dikhawatirkan akan mengabaikan hak-hak suami dan/atau anak-anaknya. Pemaknaan "jumlah/mukthirāt" dengan berlebihan dalam "intensitas ziarah" tersebut didasarkan pada teks hadis

35 Ibid., hlm. 59.

36 Abu Daud, al-Jami'., hlm. 137.

37 Ibn Hajar al-'Asqalānī, Fatḥ al-Bārī Sharh Șahīh al-Bukhārī, Juz III, 149-150; Al-Qāḍī Muhammad bin 'Abdullāh Abū Bakr bin al-'Arabī, Al-Masālik fi Sharh Muwațta' ā, Juz II, 97; Juz III, 566-567. 
pada kata "zawwārāt" (زوارات) yang mengandung makna mubālaghah. Sedangkan pemaknaan "jumlah/mukthirāt" dengan jumlah kuantitas peziarah didasarkan pada teks hadis yang mengandung kata "zā'irāt atau zuwwārāt" (زائرات-زوارات). Dengan makna ini, larangan ziarah berlaku bagi perempuan dalam jumlah banyak, berziarah bersama-sama. Boleh jadi alas an pelarangan ini tidak semata-mata karena jumlah, melainkan berhubungan dengan alasan-alasan lain yang akan disebut di bawah.

Alasan pelarangan kedua ialah karena adanya kebiasaankebiasaan pra-Islam (kebiasaan masyarakat Arab) jika masih dilakukan. Beberapa kebiasaan tersebut sebagaimana disebut oleh Abū Isḥāq al-Shayrāzī dan al-Qurțubī adalah "meratap" dengan menyebut kebaikan-kebaikan orang yang meninggal (ندب), menangis sehingga menyebabkan seluruh peserta ziarah menangis (نياحة) disertai dengan teriakan dan pekikan (الصياح), menampar pipi (لطم الخدود), dan merobekrobek saku atau baju (شق الجيوب). Kebiasaan-kebiasaan tersebut menyebabkan sebagian ulama sebagaimana disebut al-Tirmidhī tidak mengizinkan ziarah kubur bagi perempuan karena dianggap "kurang sabar dan banyak bersedih." Meski demikian, al-Tirmidhī mengakui bahwa rukhsah ziarah kubur berlaku bagi lakilaki dan perempuan.

Alasan ketiga yang menyebabkan perempuan dilarang berziarah adalah "berhias sehingga mengundang perhatian" (التبرج). Alasan ketiga ini sebagaimana disebut oleh Al-Qāộ̄ Muhammad bin 'Abdullāh Abū Bakr al-Ishbīlī al-Mālikī. Jika ditelaah lebih jauh, tiga alasan pelarangan ziarah tersebut sebetulnya bukan berasal dari kegiatan ziarah itu sendiri, melainkan bentuk "penyimpangan" dari kegiatan ziarah, yakni selain untuk instrospeksi diri dengan mengingat kematian dan mendoakan para ahli kubur. Oleh karena itu, jika kegiatan ziarah dilaksanakan dengan benar dan sesuai tujuan ziarah tidak ada alasan untuk melarang (mengharamkan) kegiatan ziarah tersebut. 
Pada awalnya ziarah kubur memang dilarang dengan maksud memelihara aqidah atau ketauhidan Allah SWT, mencegah ketergantungan kepada orang yang telah meninggal, dan menghindari kesyirikan dengan mengagung-agungkan kubur, dan menghindari banyak keluh kesah dan kurangnya kesabaran bagi wanita. Namun setelah kehawatirankekhawatiran itu hilang, ziarah kubur menjadi boleh dengan maksud menambah keimanan. ${ }^{38}$ Jadi larangan ziarah kubur adalah karena maslahah dan diperbolehkannyapun karena maslahah.

\section{Larangan menjadikan kubur sebagai tempat ibadah}

Untuk mengetahui maksud larangan ini secara komprehensif, harus diketahui terlebih dahulu makna di balik teks atau maksud di balik larangan itu. Hal ini bisa dilakukan dengan cara menghubungkan dengan riwayat lain yang semakna atau melihat asbab al-wurud dari hadis tersebut. Ada sebuah hadis yang diriwayatkan oleh Aisyah, "Rasulullah SAW bersabda: "Allah melaknat orang-orang Yahudi dan Nasrani yang menjadikan kuburan nabi-nabi mereka sebagai tempat ibadah (masjid)", kemudian dilanjutkan "maka janganlah sekali-kali kalian menjadikan kuburan sebagai masjid." Muncul pertanyaan, apa yang telah dilakukan orang-orang Yahudi dan Nasrani terhadap makam para Nabi mereka sehingga dilaknat atau dilarang oleh Allah SWT. Ternyata mereka (Yahudi dan Nasrani) menjadikan makam nabi-nabi mereka sebagai kiblat, mereka meninggalkan kiblat yang sebenarnya. Lebih jauh dari itu, sebagai ganti menyembah Tuhan, mereka menyembah nabi-nabi mereka, atau paling tidak menjadikan nabi-nabi mereka sebagai sekutu Tuhan dalam beribadah. ${ }^{39}$

Demikian halnya dengan larangan di atas, Nabi melarang umatnya dari menjadikan makam beliau dan makam lainnya sebagai masjid. Hal ini dimaksudkan agar kaum muslimin tidak berlebihan dalam mengagungkannya, sehingga menyeret

38 Abu at-Tibb, 'Aun., hlm. 60.

39 Ja'far Subhani, Tawassul, Tabarruk, Ziarah Kubur, Karamah Wali (Bandung: Pustaka Hidayah, 1995), hlm. 40. 
mereka kepada kekufuran dan kesyirikan.

3. Larangan menyalakan atau memberi lampu pada kuburan

Hadis tentang larangan menyalakan atau memberi lampu di atas harus dilihat dari segi argumentasi (dilālah) dan kandungannya. Hadis tersebut tidak dapat diterapkan secara mutlak pada semua kuburan, misalnya kuburan para nabi dan Rasul, waliyullah, imam, dan ulama shaleh. Mengagungkan kuburan mereka merupakan perwujudan dari "Ta'zīm Sya'āirallah" (pengagungan syiar-syiar Allah). ${ }^{40}$ Shafa dan Marwah yang hanya dikarenakan larian-larian kecil Siti Hajar (ibu Nabi Ismail as.) yang bukan nabi saja tergolong syiar Allah, ${ }^{41}$ apalagi jika itu adalah bekas-bekas penghulu para nabi dan Rasul yang bernama Muhammad SAW. ataupun bekas-bekas para ulama dan kekasih Allah (waliyullah) yang dinyatakan sebagai umat terbaik dan pewaris para nabi.

Hadis itu juga hanya dapat diterapkan pada hal-hal yang tidak ada manfaatnya sama sekali. Misalnya, kuburan orang yang jarang diziarahi oleh keluarga, kerabat dan sanak familinya. Dengan memberi penerangan kuburan semacam itu niscaya akan menyebabkan membuang-buang harta bukan pada tempatnya (isrāf/tabżìr) yang tidak di anjurkan dalam Islam. Artinya, larangan ini ditujukan kepada suatu keadaan di mana menyalakan lampu menjadi penyebab penghamburan harta untuk hal-hal yang kurang bermanfaat dan dikhawatirkan berimplikasi pada pengagung-agungan terhadap kuburan. ${ }^{42}$ Jadi, larangan dalam hadis tersebut lebih dikarenakan sesuatu yang lain, bukan secara mutlak menunjuk pada masalah pemberian penerangan itu sendiri.

\section{H. KESIMPULAN}

Dari berbagai uraian di atas dapat disimpulkan sebagai berikut:

40 Lihat Q.S. al-Hajj [22]: 32.

41 Lihat Q.S. al-Baqarah [2]: 158.

42 Jalaluddin, Syarh., hlm. 400. Lihat juga http://www.sarkub.com/ memberi-peneranganterhadap-kuburan/ download tanggal 21 Agustus 2017. 
1. Berdasarkan penelitian terhadap masing-masing sanad, baik dilihat dari segi adat tahammul dan ada'nya, penilaian para ulama maupun dari segi syahid dan mutabinya, dapat dikatakan bahwa sanad hadis tersebut muttaşil (bersambung), dan kualitasnya marfü", atau paling tidak menurut kriteria atTurmuzi termasuk hadis hasan sahih.

2. Terdapat tiga pendapat di kalangan para ulama kaitannya dengan larangan ziarah kubur. Pertama, mengharamkan, kedua menganggap makruh, dan ketiga membolehkan. Pada awalnya ziarah kubur memang dilarang dengan maksud memelihara aqidah atau ketauhidan Allah SWT, mencegah ketergantungan kepada orangyang telah meninggal, dan menghindari kesyirikan dengan mengagung-agungkan kubur, dan menghindari banyak keluh kesah dan kurangnya kesabaran bagi wanita.

3. Sedangkan larangan menjadikan kuburan sebagai tempat ibadah berlaku jika dikhawatirkan menyeret kepada kekufuran dan terlalu mengagung-agungkannya. Sementara larangan memberi lampu atau penerangan pada kuburan berlaku jika dianggap menghambur-hamburkan harta untuk hal-hal yang kurang bermanfaat. Jadi, apabila kekhawatiran terseret pada kekufuran, pengagungan terhadap kuburan, kurangnya kesabaran, dan penghamburan harta (illat hukum) sudah tidak ada lagi maka larangan tersebut menjadi tidak berlaku. wallahu a'lam.[] 


\section{DAFTAR PUSTAKA}

Al-Asqalani, Ibn Hajar, Tahzib at-Tahzib, Beirut: Dar al-Kutub alIlmiah, tt..

Asy'as, Abu Daud Sulaiman bin, al-Jami' as-Sahih, t.p: Dar al-Fikr, tt.

Al-Azami, M.M., Dirasat al- Had'îs al-Nabaw'ì, t.tp: Jamiah alRiyard, $1396 \mathrm{H}$.

Al-Bandari, Abdul, Sulaiman Mausu'ah, Juz II.

CD Hadis Kutub al-Tis'ah.

Hanbal, Ahmad bin, musnad, Beirut: Dar al-Fikr, tt.

http://library.islamweb.net/hadith/index.php;http://library. islamweb.net/hadith/ hadith search.php. diakses $9 \mathrm{Juli}$ 2017.

http://www.sarkub.com/memberi-penerangan-terhadap-kuburan/ download diakses tanggal 21 Agustus 2017

al-Idlibi Shalah al-Din ibn Ahmad, Manhaj Naqd al-Matn, Beirut: Dar al-Afaq al-Jadidah, 1983M/1403H.

Ismail, Syuhudi, Metodologi Penelitian Hadis, Jakarta: Bulan Bintang, 1999.

Itr, Nur, 'Ulūm al-Had' ìs, Al-Madinah al-Munawwarah: al-Maktabah al-'ilmiyyah, 1927.

Khatib, Ajjaj, Ushūl al-Had'îs"Ulumuhu wa musthalahuhu, Beirut: Dar al-ma'rifah, 1963M.

Khatib, Baghdahdi, Abu bakar bin Ali tsabit, Kitab al-Kifāyah Fì Ilm al-Riwāyah, Mesir: Matba'ah al-Sa'adah, 1972.

Khon, Abdul Majid, Ulumul Hadis, Jakarta: Amzah, 2008.

Majah, Ibn, Sunan Ibn Majah, tp: Dar al-Fikr, tt. 
Qari, Ali, Syarh Nukhbah al-Fìkr, Beirut: Dar al-Kutb al-Ilmiah, 1978M.

Al-Razi, Abu Khatim, al-Jarh wa at-Ta'dil, Haidar al-Hindi: Majlis Da'irah al-Ma'arif, 1952.

Sabbagh, Muhammad, al_hadīs al-Nabaw'ì, T.tp: al- Maktabah alIslāmi, 1997 M/1392 H).

Al-Shalah, Ibnu, 'Ulūm al-Had'ìs, Al-Madinah al-Munawwarah: alMaktabah al- Ilmiyah, 1972M.

Al-Shaleh, Subhi, "Ulum al-Had'ìs wa Musthālahuhū, Beirut: Dār alIlm Li al-Malayi, 1977.

Shiba'I, Mustafa, al-Sunnah wa Makānatuhā Fì al-Tasyrī' al-Islām, Beirut: Dar al-Qaumiyyah, 1966.

Subhani, Ja'far, Tawassul, Tabarruk, Ziarah Kubur, Karamah Wali, Bandung: Pustaka Hidayah, 1995.

Suryadi, Metode Kontemporer Memahami Hadis Nabi (Perspektif Muhammad al- ghazali dan Yusuf Qardhawi), Yogyakarta: TERAS, 2008.

Suyuti, Jalaluddin, Syarh Sunan an-Nasa’i, Beirut: Dar al-Fikr, tt.

Syamsul Haq, Abu at-Tibb Muhammad, 'Aun al-Ma'bud Syarh Sunan Abu Daud, Madinah: Maktabah al-Salafiyah, 1979.

Turmuzi, Abu Isa, al-Jami' as-Sahih Makkah: al-Maktabah atTujjariyah Mustaf Ahmad al-Baz, tt.

Turmuzi, Abu Isa, al-Jami' as-Sahih, Makkah: al-Maktabah atTujjariyah Mustaf Ahmad al-Baz, tt.

Winsink, A.J. Al-Mu'jam al-Mufahras li al-Faz al-Had'îs al-Nabaw'ī, Leaden: Breil, 1936. 